\title{
Análise da Percepção Ambiental de Estudantes no Percurso de uma Trilha Ecológica em uma Unidade de Conservação
}

\author{
Analysis of the Students' Environmental Perception on the Route of a Trail in a Conservation \\ Unit
}

\author{
Dahiane Inocência Silveira ${ }^{\mathrm{a}}$; Alvaro Lorencini Junior*b
}

\author{
${ }^{a}$ Colégio Estadual Marques dos Reis. PR, Brasil.

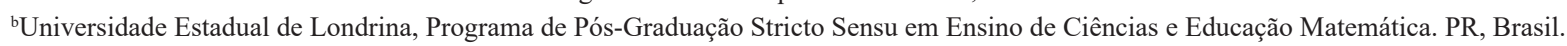 \\ *E-mail: alvarojr@uel.br
}

\begin{abstract}
Resumo
Este artigo tem como propósito socializar uma prática docente, em uma aula de campo utilizando uma trilha ecológica como recurso didático em uma unidade de conservação no município de Jacarezinho no Estado do Paraná com o intuito de potencializar a percepção ambiental dos alunos. Por meio dos roteiros elaborados pelos alunos do $6^{\circ}$ ano foram verificadas as possíveis relações entre o planejamento de uma trilha interpretativa com os objetivos da Interpretação Ambiental e dos documentos utilizados no referencial à luz da Percepção Ambiental. Nas trilhas interpretativas, a Interpretação Ambiental se torna um instrumento da Educação Ambiental ao visar objetivos que envolvem a sensibilização, a compreensão e a responsabilidade dos visitantes para com as questões ambientais. Os resultados obtidos indicam que os alunos elaboraram uma trilha interpretativa que, inconscientemente, se aproxima dos referenciais da Interpretação Ambiental.
\end{abstract}

Palavras-chave: Interpretação Ambiental. Trilha Interpretiva. Educação Ambiental.

\begin{abstract}
This article aimed to socialize a teaching practice, in a field class using a trail as a didactic resource in a conservation unit in Jacarezinho in the State of Parana to enhance the students'environmental perception. The scripts prepared by the 6th year students the possible relationships were verified between the planning of an interpretive trail with the objectives of the Environmental Interpretation and the documents used in the reference in the light of Environmental Perception. In the interpretative trails the Environmental Interpretation becomes an instrument of Environmental Education by aiming at objectives that involve the awareness, understanding and responsibility of the visitors to the environmental issues. The results indicate that the students elaborated an interpretative trail that unconsciously approaches the reference points of the Environmental Interpretation.
\end{abstract}

Keywords: Environmental Interpretation. Interpretative Trail. Environmental Education

\section{Introdução}

Quando se põe em debate os impactos ambientais da atualidade se entende que o reforço da temática no ensino se apresenta como uma enorme necessidade e única alternativa nos dias atuais. O momento é de propiciar aos alunos, cada vez com mais ênfase e urgência, uma compreensão crítica e global do ambiente, de modo a elucidar valores e desenvolver atitudes que lhes permitam adotar uma posição mais consciente e participativa no que tange às questões relacionadas à preservação, à adequada utilização dos recursos naturais e repensar atitudes frente aos fatores atuais que potencializam os impactos ambientais.

O processo interpretativo, segundo Vasconcellos (2006), é uma forma de aprender fazendo, perguntando, refletindo e respondendo. Sendo assim, é uma importante ferramenta educativa utilizada pela Educação Ambiental (EA) que permite apresentar outras nuances do ambiente ao indivíduo e, consequentemente, torná-lo sensibilizado para com as causas ambientais.
Para atingir os objetivos básicos da interpretação ambiental, muitos são os meios que podem ser utilizados, classificados em meios personalizados, que englobam interação entre o público e o intérprete, e os não-personalizados, que utilizam objetos e outros aparatos de informações visuais (MORALES, 1989).

As trilhas autoguiadas são aquelas que podem ser realizadas pelos visitantes sem o acompanhamento de monitores. Para tanto, podem ter pontos de paradas pré-determinados, nos quais juntamente com painéis, guias de campo ou folders, são disponibilizadas as informações (MOREIRA, 2008). As trilhas interpretativas, de todos os tipos, representam o mesmo tipo de desafio para quem planeja e implanta: criar consciência, incorporar apreciação e/ou sugerir uma nova maneira de pensar ou encarar algo (VASCONCELLOS, 1997). As regras e atividades devem ser organizadas de acordo com a idade, nível socioeconômico, características dos visitantes, prevendo-se os meios interpretativos e educativos a serem usados, regulamentados por normas pertinentes (IBAMA, 1999). 
Cada indivíduo tem sua maneira de perceber, reagir e responder a respeito de ações sobre o ambiente em que vive. As respostas ou manifestações daí decorrentes são resultados das percepções (individuais ou coletivas), dos processos cognitivos, julgamentos e expectativas de cada pessoa (COELHO, 2002). Dessa forma, o estudo da percepção ambiental é de fundamental importância para que se possa compreender melhor as inter-relações entre o homem e o ambiente, suas expectativas, anseios, satisfação e insatisfação, julgamentos e condutas.

A importância da pesquisa em percepção ambiental para o planejamento do ambiente foi ressaltada pela UNESCO em 1973. Uma das dificuldades para a proteção dos ambientes naturais está na existência de diferenças nas percepções dos valores e da importância dos mesmos entre os indivíduos de culturas diferentes ou de grupos socioeconômicos que desempenham funções distintas, no plano social (COELHO, 2000).

Segundo Lima (1998), as experiências ambientais propiciadas durante o percurso de uma trilha interpretativa podem ser consideradas para as práticas correlacionadas à EA na medida em que estejam vinculadas a uma visão holística e transdisciplinar, precipitando e catalisando ações e reações, organizando novos sistemas, paradigmas, exercendo a ética, definindo direitos e deveres quanto às responsabilidades para com a Terra.

A EA tem, então, uma competência e uma função transformadora, e os indivíduos têm a co-responsabilização de originar um "desenvolvimento sustentável", sendo condição para transformar a crescente degradação socioambiental. Assim, é preciso que haja um mediador na construção de referenciais ambientais e usá-los como instrumentos para o desenvolvimento de uma prática social centrada no conceito da natureza (JACOBI, 2003).

Para Loureiro (2002, p.69), a EA deve construir valores, conceitos, habilidades e atitudes que permitam a compreensão da vida, de atuação lúcida e responsável por atores sociais individuais e coletivos no ambiente como uma práxis educativa e social, contribuindo para um padrão civilizacional distinto do vigente pautado em uma nova ética da relação sociedade-natureza.

A percepção ambiental, como instrumento da EA aproxima o ser humano e o desperta para o cuidado e o respeito para com a Terra. Com isso se pode ter qualidade de vida para todos e para as novas gerações (PALMA, 2005).

Trabalhar pedagogicamente o cognitivo e o afetivo, ou seja, a razão e a emoção são essenciais para a motivação dos educandos, mas não é o suficiente. As práticas precisam ser viabilizadas e que estejam no contexto escolar a partir de projetos pedagógicos. No entanto, o problema é que nesses projetos, muitas vezes, tendem a reproduzir práticas voltadas para a mudança no comportamento do indivíduo, descontextualizada da realidade socioambiental em que estão inseridas, caindo em uma armadilha (GUIMARÃES, 2004).

Este trabalho de pesquisa tem como objetivo compreender a percepção de alunos de Ensino Fundamental em uma aula de campo em uma trilha, bem como analisar em que medida os alunos utilizam essa percepção para demonstrar os pontos da trilha que mais lhes chamou a atenção. Coube analisar, ainda, as possíveis relações que podem ser estabelecidas entre os conteúdos abordados nas aulas de Ciências, como cadeias alimentares, ciclos biogeoquímicos, relações ecológicas, entre outros, com o que pode ser visto e percebido em uma aula de campo em uma trilha ecológica.

Nesse sentido, o presente estudo além dos objetivos de pesquisa já mencionados anteriormente, tem como propósito, contribuir para a socialização de uma prática docente, que estimule a percepção ambiental dos alunos em uma aula de campo a partir de uma trilha em uma unidade de conservação no Estado do Paraná.

\section{Material e Métodos}

Os procedimentos metodológicos deste trabalho obtiveram respaldo teórico no método de Análise Textual Discursiva (ATD) de Moraes e Galiazzi (2007). Este método se organiza em quatro focos: desmontagem dos textos formando pequenas unidades de análise, exame detalhado das unidades, estabelecimento de relações entre cada unidade e captação da nova compreensão que emergiu destas relações.

Já no que tange ao processo de análise se têm três etapas sendo Unitarização, Categorização e Elaboração de Metatexto. O recorte das unidades do primeiro foco se denomina unitarização em que as partes do texto passam então a ser chamadas de unidades de análise. Portanto, é o próprio pesquisador que decide até onde poderá fragmentar o texto base podendo então, resultar unidades de análise de maior ou menor amplitude (MORAES, 2003). Preconizase, ainda, que o pesquisador deva partir para uma imersão procurando se individualizar neste processo de busca por unidades de significados.

O trabalho foi realizado com 24 alunos do $6^{\circ}$ ano de um colégio particular, com idades que variaram entre 10 e 11 anos, idade adequada para a série em questão, em que nenhum aluno havia sido reprovado em seu currículo escolar, eram 12 meninos e 12 meninas. A maioria pertencia à classe média alta e residiam em Jacarezinho, região Norte do Estado do Paraná. Apenas um aluno residia em uma cidade vizinha e apenas um aluno era bolsista, sendo morador da periferia. Todos em maior ou menor grau já haviam tido experiências extraclasse similares.

Após agendamento e planejamento prévio, foi efetuada uma visita à uma Unidade de Conservação (UC) para fazer o percurso da trilha. Mesmo surgindo comentários ou explicações no trajeto, houve dificuldades para que todos ouvissem, porque não há paradas para essas falas e, em alguns trechos, houve necessidade de se caminhar em fila única de 
modo que o último ficava muito distante do interlocutor, sendo praticamente impossível que se ouvisse o comentário. (SILVEIRA, 2013).

Em sala de aula, na escola após a prática na UC, orientamos e dividimos os alunos em 06 grupos que, a partir de suas percepções apresentaram a melhor forma de percorrer o trajeto que haviam realizado. Fizeram isso por meio de cartazes, textos descritivos do percurso, desenhos com detalhes dos elementos que chamaram atenção durante o trajeto, colagens de figuras e ilustrações. Alguns alunos registraram fotos ao longo do trajeto. Dois grupos fizeram maquetes em isopor detalhando as paradas que julgaram mais interessantes.

Solicitamos então que definissem cinco paradas, pois os principais pontos de parada da trilha devem servir para a compreensão dos temas e de acordo com Carvalho et al (2002, p. 44) existe uma limitação na capacidade de memorização do público em geral, devendo considerar que algumas pessoas poderão ter dificuldades em assimilar mais de cinco idéias.

Portanto, partindo da apresentação dos dados (cartazes e textos) dos alunos em sala, foram isoladas as descrições que cada um dos grupos fez sobre os diversos pontos da trilha. Em consonância com o processo de unitarização cada uma destas descrições foi tomada como unidade de análise (UA). Em seguida, foram isolados os elementos semânticos para a posterior definição das categorias que neste trabalho denominamos "parâmetros". Para Moraes (2003) o processo de categorização se dá pela comparação e relação entre as unidades definidas no processo inicial da análise, o que pode resultar em elementos semelhantes, os quais constituem as categorias.

Então, se no primeiro momento da análise temos um processo de separação, isolamento e fragmentação de unidades de sentido, na categorização o trabalho dá-se no sentido inverso: estabelecer relações e reunir semelhantes. Para Moraes (2003), a pretensão da ATD é a construção de um novo texto que expressa os significados e os sentidos que estavam nas entrelinhas destes textos.

Já a terceira etapa ocorre na comunicação das novas compreensões atingidas. Moraes (2003) caracteriza que um exercício de explicitação de metatextos é onde os novos insights atingidos são expressos em profundidade de detalhes. Surgem aí os argumentos centrais contidos nas categorias em que a qualidade destes metatextos ocorrem em função da intensidade com que o autor se envolve com os materiais de sua análise e os fundamentos teóricos e epistemológicos que o pesquisador se respaldou ao longo do processo.

No momento da discussão dos resultados deste trabalho houve a necessidade de codificação das unidades de análise. Esses códigos foram constituídos a partir da enumeração dos grupos, (lembrando que foram formados seis grupos); e da ordem da parada que foi definida pelo grupo para a descrição. Para a primeira informação foi utilizada a letra " $G$ " seguida do número dado ao grupo e para as paradas a letra "P", seguida do número que representa a ordem da parada que foi definida pelo grupo. Portanto, para uma unidade descrita como "segunda parada" que foi descrita pelo Grupo 3 teríamos então o código: G3P2.

Desse modo, os conceitos extraídos serão classificados em categorias temáticas que formarão os parâmetros e definiram as paradas da trilha interpretativa.

\section{Resultados e Discussão}

A primeira ação no procedimento de tratamento dos dados foi transcrever os textos dos alunos a partir dos cartazes, organizando quadros separados por grupos.

Quadro 1 - Transcrição das paradas descritas pelos alunos.

\section{\begin{tabular}{|l|l|}
\hline & Tudo começou com um projeto que tinha por objetivo
\end{tabular}} conhecer mais sobre a preservação do meio ambiente. Fomos até o Horto Florestal para saber um pouco mais sobre isso. Ao chegarmos lá fomos recebidos por um trabalhador do Horto que nos explicou sobre a importância da preservação e o desmatamento, e o que acontecia no horto. Ao entrarmos na trilha vimos várias espécies de árvores, plantas. Então andamos até que vimos um lago, paramos ali para tomar água e descansar, logo depois continuamos a trilha a professora D nos explicou um pouco sobre

Grupo as espécies de plantas, enquanto ela foi explicando o 1 que nos chamou a atenção e deixou muito triste foi o desmatamento, vimos vários troncos de árvores cortados e jogados no chão, porém continuamos a trilha e logo vimos várias plantas de espécies que não conhecíamos, então a gente se reuniu e a professora nós explicou e contou um pouco mais sobre as espécies de plantas. Porém já estava tarde quase na hora de ir embora então sentamos de baixo de uma árvore para fazer um piquenique, comemos, e depois logo o ônibus chegou para nos buscar e levar para o colégio de lá fomos para a casa foi um dia muito interessante e de bastante aprendizado.

Fomos ao Horto Florestal, quando chegamos lá a guia nos mostrou as plantações e depois fomos à trilha, começamos parando em uma descida e ela começou a explicar que ficava assim por causa das chuvas e era para ter CUIDADO porque era muito escorregadio, depois que ela terminou de explicar voltamos à caminhada, depois de cinco minutos paramos na Grupo ponte ela falou que a ponte era interessante, pois dava 2 para ver o rio e continuamos, depois de dez minutos paramos para ver as árvores, que eram importantes, como todos nós estávamos apressados continuamos a caminhada, depois paramos para ver os animais ela disse que eles são iguais a nós e merecem cuidado, como já estávamos famintos fomos logo e paramos para o lanche, essa refeição é importante para a nossa saúde e para nosso corpo.

Ponto 1 - O ponto 1 é onde o instrutor explicou o que é mata ciliar, como cuidar do meio ambiente e para ficar em silêncio e respeitar o habitat natural dos animais.

Ponto 2 - O lago está sendo habitat dos patos.

Ponto 3 - Escolhemos essa parada, pois no bimestre passado aprendemos que os líquens são uma Grupo combinação de algas e fungos, eles só se instalam 3 em lugares que tem muito oxigênio e eles são muito importantes, pois são responsáveis pela formação de partículas que poderão compor o solo.

Ponto 4 - Nesse ponto vimos árvores cortadas, e todos nós concordamos que é uma falta de respeito com o meio ambiente.

Ponto 5 - Nesse ponto as árvores naturalmente formaram um tipo de túnel ou uma mata fechada. 


\begin{tabular}{|c|c|}
\hline $\begin{array}{c}\text { Grupo } \\
4\end{array}$ & $\begin{array}{l}\text { A primeira parada foi em um lago, nós gostamos } \\
\text { porque era primeira vista do Horto. } \\
\text { A segunda parada foi em uma ponte de madeira, para } \\
\text { que a bióloga falasse da importância dos animais. } \\
\text { A terceira parada foi em uma árvore com líquens, que } \\
\text { são fungos e algas que se decompõem. } \\
\text { A quarta parada foi em duas estufas cheias de plantas, } \\
\text { para que observássemos várias espécies de flores. } \\
\text { A quinta parada foi em um belo piquenique, para } \\
\text { podermos fazer um lanche. }\end{array}$ \\
\hline $\begin{array}{c}\text { Grupo } \\
5\end{array}$ & $\begin{array}{l}\text { Eu acho que a } 1^{\mathrm{a}} \text { parada deveria ser dentro da estufa, } \\
\text { para a professora poder explicar sobre cada planta. } \\
\text { Já a } 2^{\mathrm{a}} \text { parada deveria ser em num lugar fechado com } \\
\text { animais. } \\
\text { A } 3^{\mathrm{a}} \text { parada deveria ser numa trilha para a guia do } \\
\text { horto poder falar um pouco sobre as árvores e tirar } \\
\text { nossas dúvidas. } \\
\text { A } 4^{\mathrm{a}} \text { parada deveria ser em um rio para passarmos } \\
\text { em cima e o rio deveria ser cristalino e bem limpo e } \\
\text { cuidado. } \\
\text { Já a } 5^{\mathrm{a}} \text { parada deveria ser um piquenique onde todos } \\
\text { falassem tudo que aconteceu. Nós achamos que } \\
\text { deveria ter mais animais, rios, lagos, porque iria ficar } \\
\text { mais interessante e mais legal o Horto. }\end{array}$ \\
\hline $\begin{array}{c}\text { Grupo } \\
6\end{array}$ & $\begin{array}{l}\text { 1- Quando nós começamos a trilha a orientadora } \\
\text { deveria explicar o que iria acontecer na trilha. } \\
\text { 2- Nós deveríamos fazer uma parada para observar os } \\
\text { animais e as plantas. } \\
\text { 3- Deveria ter um lago com água cristalina e plantas } \\
\text { e peixes raros. } \\
\text { 4-Deveria ter placas de identificação nas espécies de } \\
\text { vegetais. } \\
\text { 5- Deveria ter um engenheiro florestal no final } \\
\text { oferecendo uma árvore. }\end{array}$ \\
\hline
\end{tabular}

Fonte: dados da pesquisa.

Analisando a produção de cada grupo sobre as percepções que expressaram acerca de seus trajetos à luz de Reigota (1995) nota-se que G1 e G4 apresentam uma visão naturalista do ambiente, na qual o ser humano é um espectador da natureza, em que se evidenciam aspectos naturais, confundindo-se com conceitos ecológicos do ecossistema. Inclui, ainda, aspectos físicos - químicos, a fauna e a flora, mas exclui o ser humano deste contexto. Em todas as paradas as descrições dos grupos tendem para este aspecto. Talvez, a única que reconheça uma ação antrópica seria o disposto na unidade G1P3 que trata sobre o desmatamento.

Ainda, sob essa perspectiva, G2 e G6 pontuaram a totalidade de suas descrições sob uma visão globalizante na qual o meio ambiente é caracterizado como as relações entre a natureza e a sociedade e na qual o homem é um ser social que deve conviver em harmonia com a natureza. Exceção feita na unidade G6P4, em que se sugere a fixação de placas no ambiente para identificação das espécies podendo gerar impactos.

Já o G3 apresentou uma leitura que se divide entre as duas visões discutidas anteriormente, pois entre as cinco paradas, em três apresentam uma visão naturalista sendo elas compostas por relações entres os conteúdos escolares e as observações feitas na trilha onde na verdade os alunos atuam como observadores e as descrições apontam para constatações sem envolvimento de detalhes, que façam alusão às interferências ou relações do homem e natureza. Nas unidades G3P1 e G3P4 há claramente uma visão globalizante, posto que se ressalta um tipo de relação entre homem e natureza. Na primeira se pede o respeito ao habitat natural, e na segunda se consta-se que este respeito foi quebrado.

Já o G5 possui uma visão antropocêntrica que segundo Reigota (1995), o meio ambiente é reconhecido pelos seus recursos naturais, mas que são de utilidade para o homem. Para esse grupo a UC tem uma conotação de parque, no qual está numa relação para a satisfação do homem e não tão somente para ser refúgio natural dos animais e, portanto, livre de transformações.

A característica que mais se destacou nos textos são as intenções de cada grupo. Cada um apresentou uma forma singular de perceber o espaço, seja este apresentado como uma trilha, um ambiente de recreação, um passeio no bosque, sendo que se observou nas sentenças os elementos semânticos que denotam a percepção da trilha.

Desse modo, os conceitos extraídos por meio da percepção são classificados em categorias temáticas, que formam os parâmetros e que, posteriormente, irão definir as paradas que podem compor uma trilha interpretativa na percepção dos alunos dessa faixa etária. É com base nessa análise que se pode juntar todas as paradas dos seis grupos e formar a trilha ideal percebida por estes alunos neste trabalho.

Foram definidas então duas categoriais sendo a primeira a categoria chave, a qual se chamará de tema da parada e, em segundo plano, a categoria subordinada que se chamará de motivadores.

Para que se possa contextualizar os elementos se traz para a discussão os temas de paradas e os seus motivadores. Cada descrição de parada apontada pelo grupo será uma unidade de análise e receberá um código próprio que identifica o grupo e a ordem da parada (ex: G1P1) definido pelo grupo 1 na primeira parada.

É pertinente ressaltar que um tema de parada pode ser apresentado em mais de uma UA com motivadores diferentes.

Quadro 2 - Temáticas, Motivadores e Unidades de Análise

\begin{tabular}{|c|c|c|}
\hline Temáticas & Motivadores & $\begin{array}{c}\text { Unidade de } \\
\text { Análise (UA) }\end{array}$ \\
\hline $\begin{array}{l}\text { Parada para } \\
\text { explanação } \\
\text { inicial }\end{array}$ & $\begin{array}{l}\text { Explicação antes do início do } \\
\text { trajeto }\end{array}$ & $\begin{array}{l}\text { (G1P1) } \\
(\mathrm{G} 3 \mathrm{P} 1) \\
(\mathrm{G} 6 \mathrm{P} 1) \\
\end{array}$ \\
\hline $\begin{array}{l}\text { Parada com o } \\
\text { tema cuidados } \\
\text { na trilha }\end{array}$ & $\begin{array}{l}\text { O alerta quanto ao risco de } \\
\text { queda }\end{array}$ & (G2P1) \\
\hline \multirow[t]{2}{*}{$\begin{array}{l}\text { Parada com } \\
\text { tema corpos } \\
\text { d'água }\end{array}$} & Estética da natureza & $\begin{array}{l}\text { (G1P2) } \\
\text { (G2P2) } \\
\text { (G4P1) } \\
\text { (G5P4) } \\
\text { (G6P3) }\end{array}$ \\
\hline & $\begin{array}{l}\text { A importância dos corpos } \\
\text { d'água no ecossistema }\end{array}$ & (G3P2) \\
\hline $\begin{array}{l}\text { Parada com o } \\
\text { tema fauna }\end{array}$ & $\begin{array}{l}\text { Contemplação e preservação } \\
\text { da fauna }\end{array}$ & $\begin{array}{l}(\mathrm{G} 2 \mathrm{P} 4) \\
(\mathrm{G} 4 \mathrm{P} 2) \\
(\mathrm{G} 5 \mathrm{P} 2)\end{array}$ \\
\hline
\end{tabular}


..continuação

\begin{tabular}{|c|c|c|}
\hline Temáticas & Motivadores & $\begin{array}{c}\text { Unidade de } \\
\text { Análise (UA) }\end{array}$ \\
\hline $\begin{array}{l}\text { Parada } \\
\text { com o tema } \\
\text { desmatamento }\end{array}$ & $\begin{array}{l}\text { Qual o motivo de derrubada } \\
\text { de árvores em uma UC? }\end{array}$ & $\begin{array}{l}(\mathrm{G} 1 \mathrm{P} 3) \\
(\mathrm{G} 3 \mathrm{P} 4)\end{array}$ \\
\hline \multirow[b]{3}{*}{$\begin{array}{l}\text { Parada com } \\
\text { tema flora }\end{array}$} & $\begin{array}{l}\text { Estabelecer pontes com } \\
\text { conteúdos escolares }\end{array}$ & $\begin{array}{l}\text { (G3P3) } \\
\text { (G4P3) }\end{array}$ \\
\hline & $\begin{array}{l}\text { Uso de placas para } \\
\text { identificação de espécies }\end{array}$ & (G6P4) \\
\hline & $\begin{array}{l}\text { Explanação sobre as } \\
\text { características } \\
\text { das espécies vegetaíficas }\end{array}$ & $\begin{array}{l}\text { (G1P4) } \\
\text { (G2P3) } \\
\text { (G3P5) } \\
\text { (G4P4) } \\
\text { (G5P1) } \\
\text { (G5P3) }\end{array}$ \\
\hline $\begin{array}{l}\text { Parada com } \\
\text { tema composto } \\
\text { fauna e flora }\end{array}$ & Contemplação da natureza & (G6P2) \\
\hline \multirow{2}{*}{$\begin{array}{l}\text { Parada } \\
\text { recreativa }\end{array}$} & $\begin{array}{l}\text { A confraternização e o lado } \\
\text { recreativo de uma visita às } \\
\text { UC }\end{array}$ & $\begin{array}{l}\text { (G1P5) } \\
(\mathrm{G} 2 \mathrm{P} 5) \\
(\mathrm{G} 4 \mathrm{P} 5)\end{array}$ \\
\hline & $\begin{array}{l}\text { A importante troca de ideias } \\
\text { sobre o que foi percebido }\end{array}$ & (G5P5) \\
\hline $\begin{array}{l}\text { Parada com } \\
\text { tema incentivo à } \\
\text { preservação }\end{array}$ & $\begin{array}{l}\text { Formas de incentivo à } \\
\text { preservação }\end{array}$ & (G6P5) \\
\hline
\end{tabular}

Fonte: dados da pesquisa.

Três grupos fizeram referência à explicação dada pelos profissionais da UC antes do início do trajeto, G1P1, G3P1 e G6P1 originando o motivador: Importância da explicação antes do trajeto. Pertinente ressaltar que estas explicações iniciais efetuadas pela guia foram explanações sobre segurança, localização de banheiros e outros aspectos técnicos normativos da realização do trajeto. Não houve neste momento nenhum tipo de antecipação sobre pontos específicos de observação na trilha.

Todos os grupos que fizeram o trajeto fizeram paradas em que o ponto central foi referente às plantas ou às árvores. É natural que esta seja a abordagem mais comum, pois é provável que para as atividades de Interpretação Ambiental em trilhas, as árvores sejam os elementos mais importantes, pois estruturam a floresta denominando o tipo de ecossistema, presentes na vida humana nos alimentos, nos móveis, nos remédios, etc. (SILVA e LORENCINI JR, 2010).

Destacam-se três motivadores referentes à temática das plantas sendo esses: - 1 - Estabelecer pontes com os conteúdos escolares, 2 - Uso de placas e 3 - Explanação sobre as características das espécies vegetais.

De acordo com o Grupo Temático de Interpretação Ambiental do Projeto Doces Matas (2002), a utilização de placas em unidades de conservação é um elemento bastante recomendado quando se tratar de trilhas autoguiadas. Em trilhas guiadas, já que há monitores dando explicações, as placas podem ser dispensadas, visto que o ambiente se torna mais harmonioso na ausência delas.

No entanto, no caso desta unidade, o que se pode observar na descrição citada é uma sugestão de utilização de placas que poderiam agilizar o processo de reconhecimento de algumas espécies sem ser necessário recorrer ou aguardar a explicação do guia. Sem tomar o que dispõe o referencial como regras absolutas, se poderia inferir que estas identificações sugeridas na unidade G6P4 se aplicadas apenas em um determinado ponto do trajeto têm mais vantagens que desvantagens, considerando quão prático isto se tornaria no sentido de esclarecer a curiosidade do visitante.

$\mathrm{Na}$ unidade G2P1 há uma referência ao aspecto escorregadio da descida, salientando a explicação proferida pela guia quanto à causa deste processo. Nota-se uma observação muito pertinente a estes aspectos das trilhas, posto que alguns teóricos da interpretação recomendem um cuidado especial, por parte do manejo das unidades, no sentido de providenciar degraus em lugares os quais sejam caminhos das águas mais susceptíveis a se tornarem escorregadios após as chuvas.

Antes de começar a construção, é aconselhável que se observe atentamente, as características do local. Conforme as indicações de elaboração de trilha, primeiramente é necessário analisar a composição do solo, qual é sua constituição e como esse se comporta durante o período das chuvas. Tomando estes cuidados poderá se evitar a erosão (PROJETO DOCE MATAS, 2002, p. 83).

Não se poderia dizer que a trilha retratada neste trabalho denota que houve um bom prospecto acerca dos riscos, mas a guia fez o mínimo ao alertar os alunos. O grupo em questão, porém deu a devida importância a este alerta ao ponto de relembrá-lo no ato de elaboração dos roteiros.

Representado em três grupos e em três paradas distintas, os corpos de água como elemento da natureza estética compõem as descrições que apontam quais são as visões conceituais em que se apresenta uma forma de percepção estética. De acordo com Serrão (2004), o que compõe a experiência estética da natureza é a vital diversidade dos sentidos, a visão, a audição, o tato e o olfato. A contemplação das cores e das tonalidades de luz, mas também perceber os cheiros peculiares de cada estação, os sabores, as texturas e os sons da água.

$O$ rio então é um motivador de parada para contemplação e, ainda, sob esta mesma ótica, a unidade G5P4 há a sugestão que se use como parada um ponto no qual houvesse uma ponte sobre um rio bem cuidado e de águas cristalinas. Essa descrição aponta para um elemento inexistente na trilha sugerindo que deveria existir. Não há outra intenção nesta unidade que não seja a disposição de um elemento estético e que esse torne a caminhada pela trilha mais atraente. Há que considerar também que essa unidade predispõe a ação antrópica como forma de tornar um ambiente mais agradável e mais atraente aos visitantes.

Sob outra ótica da percepção estética, a unidade G1P2 apresenta o lago como um ponto para descanso, o que é compreensível, haja vista que se alguém tiver que optar para descansar à beira de um rio ou outro lugar, certamente, optará 
pelo primeiro por razões óbvias. A percepção estética toma o ambiente assim como ele se apresenta, notando imediatamente o que toca os sentidos. Em um nível de sensibilidade que não se atrela aos aspectos que circundam este ambiente ou que estão por detrás da aparência do ambiente, atentando somente ao ambiente sensível sem que este seja intelectualizado. (MARIN, 2006).

Tilden (1977 apud VASCONCELLOS, 2006) diz que as pessoas se interessam pelo que toca sua personalidade, experiência e ideais, aquilo que lhes parece relevante. Neste parâmetro são incluídas as unidades que fazem referência aos animais da UC colocando-os como elemento principal da parada. Destacando a contemplação e preservação da fauna.

Nas unidades G2P4 e G4P2 há descrições de parada do grupo que realçam as explanações da guia com relação aos animais. É necessário esclarecer que os animais citados se resumem às espécies da fauna silvestre como patos, pássaros e preás que fugiam aqui e ali assustados. Em certo trecho se tem uma fala que diz que a parada deveria ser em um local no qual os animais estivessem fechados. Tal afirmação é uma clara alusão a algo comum em zoológicos em que o fato de os animais estarem restritos a um espaço delimitado faz com que sua observação seja facilitada. Anuncia que os alunos não fizeram uma inferência de que em uma UC os animais ficam livres, diferindo assim de um zôo. Destaca-se a sugestão da inferência antrópica na UC, ao considerar que os animais sejam criados em alguma espécie de cercado deixando implícito o posicionamento do grupo de que a unidade deveria providenciar essa condição.

Diante da grave crise ambiental para a manutenção da vida no Planeta não se pode destinar a EA apenas para um único público, não se pode apostar na transformação do jovem hoje para se ter uma sociedade transformada amanhã, não há tanto tempo para essa espera. Esse processo educativo ocorre na relação com a realidade socioambiental, em uma relação dialética de transformação do indivíduo e da sociedade; portanto, o público da EA deve ser a sociedade com seus atores individuais e coletivos, em todas as faixas etárias. (GUIMARÃES, 2004).

As trilhas interpretativas desempenham a importante função de oferecer às pessoas a oportunidade da relação homem-natureza mais responsável e sustentável, desse modo, unidades de conservação que oferecem essa prática ao público proporcionam esse reencontro (VASCONCELLOS, 2006). Possibilitar aos alunos essa experiência contribui para sua aproximação com o meio que os cerca.

Então, quando se tem o questionamento: "Qual o motivo de derrubada de árvores em uma UC?" O que se nota são reações de contrariedade apontando para a temática do desmatamento. Deve-se esclarecer, porém que o corte de árvores de determinadas espécies é comum em UC por se tratar de um de manejo em que são extraídas espécies não nativas da região que podem se tornar praga, colocando em risco a sobrevivência das espécies nativas. É compreensível que os alunos subentenderam que a UC estava sendo desmatada. Os troncos cortados, porém, são um provocador e estimulam discussões acerca do tema. Loureiro (2004) chama a atenção para a necessidade de superação das propostas educativas ambientais ingênuas e descomprometidas, social e politicamente, em busca de atividades mais consistentes e, consequentemente, comprometidas com a construção de sociedades mais justas e igualitárias.

A EA é capaz de atuar na formação de sujeitos sociais críticos, participativos, que se pautem pela construção de uma sociedade em que a sustentabilidade seja entendida também como democracia, equidade, justiça, autonomia e emancipação, como são referências neste estudo. Isso significa superar a ideia, muito presente nas propostas de Educação Ambiental, de que a EA tem como objetivo a mudança de comportamento dos sujeitos em busca de comportamentos considerados ambientalmente corretos, configurando-se, como preconiza Brügger (1994 apud TOZONI-REIS, 2006) em um adestramento ambiental.

O tema fauna e flora foi apontado em uma unidade de análise que continha tanto referência à flora quanto à fauna de modo que houve a necessidade de criar uma categoria de temática composta por motivadores de contemplação da natureza.

Em relação ao Ensino Fundamental, Frey et al. (2006) comentam que tais atividades educativas são necessárias pelo fato de que as crianças disseminam os conhecimentos que recebem. Muitas gostam de brincar com as rochas e água, que juntamente com o tempo, são temas centrais da geologia, que dão às crianças a oportunidade de aprender mais sobre a Terra e as belezas naturais que a compõe, o que deve ocorrer o mais cedo possível. Portanto, para introduzir a temática, a curiosidade é o melhor argumento que os professores podem utilizar, em que as crianças devem apreciar os elementos naturais, observando, identificando e tirando as suas próprias conclusões.

A produção de mudas de árvore é uma das atividades da UC e o grupo sugere que uma muda seja doada a cada visitante. A busca por refúgios naturais e o gosto pela aventura incita as pessoas a percorrerem caminhos, os quais possibilitam a interação com os lugares. Alternativas para trabalhos educativos em atividades de campo a partir da análise de seus recursos e da interpretação de suas belezas, as trilhas interpretativas são ferramentas úteis no processo de construção da cidadania ecológica. Tomando as precauções necessárias a respeito de planejamento seria uma ótima provocação e incentivo.

Tem-se também, nesse sentido, que buscar a superação do caráter moralista e moralizante, observado em algumas ações educativas ambientais visando construção da educação ambiental crítica e emancipatória. (TOZONI-REIS, 2006).

A EA não deve estar restrita à dimensão ecológica, mas a uma visão contextualizada a realidade ambiental, com proeminência na incorporação efetiva dos aspectos 
socioeconômico-culturais. (GOMES, 2012).

Ao final do trajeto, 4 grupos - G1P5, G2P5, G4P5 e G5P5 abordam este momento de recreação e confraternização com os colegas.

Nas quatro unidades há nuances diferenciadas na forma de abordagem ao final do trajeto e ao piquenique no qual se sobressai a sugestão de troca de ideias, uma atividade de debate e intercâmbio de impressões sobre a atividade. Estas unidades promovem o apontamento de uma atividade com tons de recreação. O próprio ato de ir até um parque pode ser tomado como recreação pelos alunos e o piquenique seria como último ato, uma confraternização de fechamento e um momento de reposição de energia.

Hardok (2008) defende o uso de oficinas, como uma tentativa pedagógica de rebater a forma tradicional de ensino, com atividades reflexivas abertas para a realidade e a construção de conceitos. Dessa forma, o aluno percebe que também faz parte do meio ambiente e pode observar que suas ações têm a capacidade de alterar o mesmo, ou seja, tudo está integrado em uma dinâmica complexa.

Reigota (1991) ressalta ser indispensável conhecer as concepções dos alunos sobre meio ambiente, pois torna possível uma melhor condição de realizar atividades de Educação Ambiental.

Segundo Trapp, Gross e Zimmerman (1994), de um modo geral, as caminhadas em ambientes naturais são muito gratificantes e despertam o interesse e a curiosidade dos usuários, predispondo-os a buscar e a receber informações relacionadas ao local. Quando a interpretação é feita nestes locais, facilita para as pessoas a conexão já desejada, geralmente, com bons resultados. Conforme Kant (2003), não se vê a realidade como essa é, mas como a pessoa é. Utiliza-se o sentido seletivo, segundo os interesses, pensamentos, estado da alma, sentido motivacional, expectativas do futuro e quase sempre ao sentido do prazer.

Sendo assim, a trilha ideal seria organizada de acordo com o Quadro 3.

Quadro 3 - A trilha, de acordo com as percepções dos alunos

\begin{tabular}{|c|c|}
\hline 1-Parada com tema: Flora & $\begin{array}{l}\text {-Explanações sobre formações vegetais; } \\
\text {-Estabelecer pontes com conteúdo escolares; } \\
\text {-Uso de placas para identificação de espécies vegetais atentando para o nome popular e/ } \\
\text { ou nome científico da planta ou árvore; } \\
\text {-Explanação sobre as características específicas das espécies vegetais. }\end{array}$ \\
\hline 2-Parada com tema: Corpos d'água & $\begin{array}{l}\text {-Estabelecer um intervalo de tempo para que o grupo contemple e relaxe (este processo } \\
\text { é muito importante para despertar no visitante o desejo de preservar); } \\
\text {-Discorrer sobre a importância dos animais aquáticos atentando para uma breve } \\
\text { explanação acerca dos ecossistemas aquáticos. }\end{array}$ \\
\hline $\begin{array}{l}\text { 3- Parada com tema composto: Fauna e } \\
\text { Flora }\end{array}$ & $\begin{array}{l}\text {-Estabelecer um ponto com características de mirante se possível para um curto espaço } \\
\text { de contemplação do ambiente no entorno; } \\
\text {-Explanar sobre o ecossistema da UC, falar de forma breve como esta foi formada, quais } \\
\text { os animais e vegetais mais comuns, o trajeto dos cursos de água, onde nascem, são } \\
\text { afluentes de qual rio; } \\
\text {-Discorrer sobre a preservação da fauna, definindo entre os animais nativos aqueles que } \\
\text { podem estar em extinção. }\end{array}$ \\
\hline 4-Parada com tema: Desmatamento & $\begin{array}{l}\text {-Discorrer sobre o desmatamento; } \\
\text {-Falar sobre o motivo de derrubada de árvores em uma UC. }\end{array}$ \\
\hline $\begin{array}{l}\text { 5-Parada com tema: Incentivo à } \\
\text { preservação }\end{array}$ & $\begin{array}{l}\text {-A UC pode definir algum tipo de incentivo prático à preservação. O ideal talvez fosse } \\
\text { que a UC definisse um local para reflorestamento e fizesse com que o visitante tomasse } \\
\text { parte no processo ao plantar uma muda. }\end{array}$ \\
\hline Final do trajeto e recreação & $\begin{array}{l}\text {-A recreação no final do trajeto deve obedecer a alguns critérios, um piquenique pode } \\
\text { ser inofensivo desde que os visitantes tomem cuidados específicos com o lixo que pode } \\
\text { ser produzido. Dentro desta mesma esfera recreativa está a confraternização entre os } \\
\text { visitantes o que também é um elemento relevante do ponto de vista da sensibilização. } \\
\text { Este é o momento mais propício para uma efetiva troca de impressões acerca do que } \\
\text { cada um percebeu. } \\
\text {-Na UC existem lixeiras personalizadas para separação do lixo: Plástico, papel... E no } \\
\text { final cada um colocou seu lixo nas lixeiras especificas para tal. }\end{array}$ \\
\hline
\end{tabular}

Fonte: os autores.

A ordem de algumas paradas pode ser alterada de forma que fique mais adequada. Tanto a explanação inicial quanto o ponto final do trajeto no qual ocorre o piquenique, embora tenham sido tratados pelos alunos como paradas, não constam dentro das 05 paradas recomendadas pelos teóricos da Interpretação Ambiental, pois não integram elementos localizados no trajeto da trilha, porém devem ser consideradas como partes fundamentais do todo que compreende a atividade de visitação, pois são os elementos que emolduram e reforçam aquilo que pode ser aproveitado e construído dentro do trajeto.

\section{Conclusão}

Uma trilha é considerada interpretativa quando seus recursos naturais são traduzidos para os visitantes por meio de temas pré-definidos com recursos didáticos, tais como placas, folhetos e guias especializados. Na prática, as trilhas 
interpretativas têm o propósito de estimular, provocar as pessoas às novas percepções, com o objetivo de levá-las a observar, questionar, experimentar, sentir e descobrir os vários sentidos e possibilidades de significados relacionados a um tema previamente selecionado.

O planejamento de pontos da trilha após a visita foi eficiente para se identificar a percepção de diversos aspectos dos alunos. Desse modo, foi possível encontrar locais nos quais a sensibilização dos visitantes, no que tange à interpretação ambiental, poderá ser maior. Assim, esperase que o planejamento ora proposto venha a ser aplicado em pesquisas futuras, e até mesmo para uso interno da UC, almejando identificar se é possível, por intermédio dos pontos escolhidos, despertar nas pessoas a necessidade e a vontade de empreenderem ações em prol da conservação ou da recuperação do meio natural que as cerca.

A confecção dos cartazes, maquetes, slides com fotos, as falas para apresentação dos grupos, as provocações causadas pelo ambiente, da percepção individual que foi exteriorizada proporcionou a discussão coletiva e tornou o roteiro possível, a partir do consenso de quais fatores se repetiram na visão desses alunos.

A pesquisa destacou a importância de aulas extraclasse, em um ambiente de preservação, com intuito de estimular a percepção ambiental dos alunos para os recursos naturais que estão ao redor das pessoas e de como estes podem ser utilizados para provocar o cuidado com o ambiente e propostas de aulas que permitam utilizar uma trilha como recurso didático.

\section{Referências}

CARVALHO, F.N. et al. Manual de introdução à interpretação ambiental. Belo Horizonte: SEGRAF, 2002.

COELHO, A.J. A importância do desenvolvimento sustentável. 2000. Disponível em: <http://www.idcb.org.br/documento/ artigos 2301/aimportancia.doc >. Acesso em 10 jan. 2021.

COELHO, A.J. Percepção ambiental dos alunos da faculdade brasileira. 2002. Disponível em:

$<$ http://www.abe_es.org.br/paginas/trabalhos/ percep $\%$ e $7 \%$ e3\%20ambiental\%20u.pdf> Acesso em: 10 jan. 2021.

FREY, M.L. et al. Geoparks: a regional european and global policy. In: DOWLING, R; NEWSOME, D. (Ed.) Geotourism. Oxford: Elsevier Butterworth Heinemann. 2006. p.95-118.

GOMES, I.S. Concepções de educação ambiental dos alunos do $3^{\circ}$ ano do ensino médio do Colégio Estadual Paulina Pacifico Borsari na cidade de Rancho Alegre. Londrina: UEL, 2012.

GUIMARÃES, M. Educação Ambiental Crítica. In: LAYRARGUES, Philippe Pomier. Identidades da educação ambiental brasileira. Brasília: Ministério do Meio Ambiente, 2004. p.26-33.

HARDOK, R.B.F. Educação ambiental com desenvolvimento de atividades interdisciplinares na $5^{a}$ serie no ensino fundamental. Porto Alegre: Universidade Federal de Santa Maria, 2008.

IBAMA - Instituto Brasileiro de Meio Ambiente e Recursos Naturais Renováveis. Guia de chefe de unidades de conservação. 1999. Disponível em <http://www.ibama.gov.br/siucweb/ guiadechefe/guia/m-2corpo.htm> Acesso em: 22 dez. 2020.

JACOBI, P. Educação ambiental, cidadania e sustentabilidade. Cad. Pesq., n.118, p.189-205, 2003. doi: https://doi.org/10.1590/ S0100-15742003000100008.

KANT, I. Crítica da razão prática. São Paulo: Martin Claret, 2003.

LIMA, S.T. Trilhas interpretativas: a aventura de conhecer a paisagem. Cad. Paisagem. n.3, p.39-44, 1998.

LOUREIRO, C.F.B. Educação ambiental e movimentos sociais na construção da cidadania ecológica e planetária. In: LOUREIRO, C.F.B.; LAYRARGUES, P.P.; CASTRO, S.C. (Org.) Educação ambiental: repensando o espaço da cidadania. São Paulo: Cortez, 2002. p.69-98.

LOUREIRO, C.F.B. Educação ambiental transformadora. In: LAYRARGUES, P.P. Identidades da educação ambiental brasileira. Brasília: Ministério do Meio Ambiente, 2004. p. 6571.

MARIN, A.A. Educação ambiental nos caminhos da sensibilidade estética. Inter-Ação, v.31, n.2, p.277-290, 2006.

MORAES, R. Uma tempestade de luz: a compreensão possibilitada pela análise textual discursiva. Ciênc. Educ., v.9, n.2, p.191-211, 2003. doi: https://doi.org/10.1590/S1516-73132003000200004.

MORAES, R. GALIAZZI, M.C. Análise textual discursiva. Ijuí: Unijuí. 2007.

MORALES, J. Un recorrido por la interpretación. Taller Internacional sobre interpretación ambiental en áreas silvestres protegidas. Chile: FAO/PNUMA Informes, 1989. p.5-60.

MOREIRA, J.C. Patrimônio geológico em unidades de conservação: atividades interpretativas, educativas e geoturísticas. Florianópolis: UFSC, 2008.

PALMA, I.R. Análise da percepção ambiental como instrumento ao planejamento da educação ambiental. Porto Alegre: Universidade Federal do Rio Grande do Sul, 2005.

PROJETO DOCE MATAS/GRUPO TEMÁTICO DE INTERPRETAÇÃO AMBIENTAL. Manual de introdução à interpretação ambiental. Belo Horizonte, 2002.

REIGOTA, Marcos. Fundamentos teóricos para a realização da educação ambiental popular. Programa de Educação Popular Ambiental/ICAE. Em Aberto, v.10, n.49, 1991.

REIGOTA, M. Meio ambiente e representação social. São Paulo: Cortez, 1995.

SERRÃO, A.V. Filosofia e paisagem: aproximações a uma categoria estética. 2004. Disponível em: <http://www. centrodefilosofia.com/uploads/pdfs/philosophica/23/5.pdf $>$. Acesso em 27 jan. 2021.

SILVA, D.M.; LORENCINI JR, A. A relação entre trilhas interpretativas, interpretação ambiental e educação ambiental, e a importância das espécies arbóreas para essas atividades. 2010. Disponível em <http://www.pg.utfpr.edu.br/sinect/anais2010/ artigos/Ens_Cien/art160.pdf>. Acesso em: 16 abr. 2021.

SILVEIRA, D. I. Processo de criação de uma trilha interpretativa a partir da percepção ambiental de alunos do ensino fundamental. 102 fls. Dissertação de Mestrado do Programa de Pós-graduação: Ensino de Ciências e Educação Matemática. Universidade Estadual de Londrina, Londrina, 2013.

TOZONI-REIS, M. F. de C. Temas ambientais como "temas geradores": contribuições para uma metodologia educativa ambiental crítica, transformadora e emancipatória. Educar em Revista, n.27, p. 93-110, 2006. doi: https://doi.org/10.1590/ 


\section{S0104-40602006000100007.}

TRAPP, S.; GROSS, M.; ZIMMERMAN, R. Signs, trails and waside exhibits, connecting people and places. Interpreters's Hanbook Series, USA, 1994.

VASCONCELLOS, J.M.O. Trilhas interpretativas como instrumento de educação. In: CONGRESSO BRASILEIRO DE UNIDADES DE CONSERVAÇÃO, 1, Curitiba-PR. Anais, v. 1. IAP; Unilivre: Rede Nacional Pró Unidade de Conservação. 1997. p 465- 477.

VASCONCELLOS, J.M.O. Educação e interpretação ambiental em unidades de conservação. Cad. Conserv., v.3, n. 4, 2006. 